\title{
EFFECTS OF DANCE TRAINING PROGRAMME ON POSTURAL STABILITY OF MIDDLE AGED WOMEN
}

\author{
Radmila Kostić1, Slavoljub Uzunović1, Tijana Purenović-lvanović1, Đurđica Miletićć, Georgija Katsora ${ }^{3}$, Saša \\ Pantelić ${ }^{1}$, Zoran Milanović ${ }^{1}$ \\ ${ }^{1}$ Faculty of Sport and Physical Education, University of Niš, Niš, Serbia \\ ${ }^{2}$ Faculty of Kinesiology, University of Split, Split, Croatia \\ ${ }^{3} \mathrm{GEL}$, Teofilou and Bolanaki, Ano Liosia, Athens, Greece
}

\begin{abstract}
SUMMARY
Aim: The aim of the study was to determine the effects of Greek folk dancing on postural stability in middle age women.

Methods: Sixty-three women aged from 47-53 participated in this study. All participants were randomly divided into the experimental group -33 participants (mean $\pm S D$; body height $=160.13 \pm 12.07 \mathrm{~cm}$, body mass $=63.81 \pm 10.56 \mathrm{~kg}$ ), and the control group -30 participants (mean $\pm S D$; body height $=160.63 \pm 6.22 \mathrm{~cm}$, body mass $=64.79 \pm 8.19 \mathrm{~kg}$ ). The following tests were used to evaluate the motor balance and posture stability of participants; the double-leg stance along the length of a balance beam (eyes open), the double-leg stance along the width of a balance beam (eyes open), the single-leg stance (eyes open) and the double-leg stance on one's toes (eyes closed). The Functional Reach Test for balance and the Star Excursion Balance Test were used to evaluate dynamic balance.

Results: The multivariate analysis of covariance of static and dynamic balance between participants of the experimental and control group at the final measuring, with neutralized differences at the initial measuring (Wilks' $\lambda=0.45$ ), revealed a significant difference $(p<0.05)$. The intergroup difference at the final measuring was also found to be significant $(p<0.05)$ for the following variables; the double-leg stance on one's toes, the Functional Reach Test, balance of the right anterolateral, balance of the right posterolateral and balance of the left posteromedial.

Conclusion: An organized dance activity programme does lead to the improvement of static and dynamic balance in middle aged women.
\end{abstract}

Key words: dance, posture stability, dynamic balance, women

Address for correspondence: Z. Milanović, Faculty of Sport and Physical Education, University of Niš, Čarnojevića 10a, 18000 Niš, Serbia. E-mail: zoooro_85@yahoo.com

\section{INTRODUCTION}

Postural stability, dynamic and static balance are used to refer to special motor skills used to maintain static and dynamic of the body (1). Balance is studied either along with the rest of coordination skills or serperately as a special motor skill. We can talk about balance in the eyes-open or eyes-closed conditions, the prop balancing factor or body balancing factor with no props and finally static or dynamic balance.

Within the scope of this research, postural stability was studied as a special motor skill. The motor ability to sustain balance is especially important for people around fifty years of age and older due to various changes which are primarily manifested by the decline in motor skills, which in turn leads to changes in the quality and quantity of the range of motion (2). Loss of balance confidence is a frequent condition that affects $20-75 \%$ of the community-dwelling elderly population, especially women going through or coming out of menopause (3). Although a recent fall is a common trigger, loss of balance confidence also appears independently of previous experiences with falls. Maintaining or improving balance confidence is important to avoid unnecessary, self-imposed restrictions of activity and subsequent disability (3). Holding another person's hand or using an assistive device while walking are simple and natural interventions that are used to address poor balance confidence in daily life. However, more complex interventions have also been developed and tested to achieve more sustained improvement in balance confidence (3).

Special significance, while achieving and sustaining balance and body position during quiet standing or during motion, is given to systems of organs such as the nervous system, muscle system, skeletal system, visual system, proprioceptive and vestibular system (4). With age, the functions of these systems change, in other words, these systems begin to function in a reduced manner and so the risk for balance deficits and deficits in other motor skills increase, which in turn leads to greater risks of falling (5). Functional balance which allows for normal motor maintenance is a consequence of the harmonious reactions of organs which systematically and with no errors pass precise and correct information to the nervous system regarding the balance of the body either when quietly standing or during motion. The brain receives information on the strength-intensity, time-speed of the motion and other characteristics of movement and motions from sensory receptors, which are located in the eyes, inner ear, joints, muscles, and skin (6). Proprioceptive receptors which can be found in the muscle tendons and which provide so-called "kinesthetic sensitivity" (kinesthesia) or "muscle sensitivity" are especially important (6).

Various external factors influence the development and maintenance of body balance: cognitive factors caused by fear of 
falling, specific neural diseases (dementia), various medication, overall health, the time of a day (7). In order to determine the causes of any possible changes that take place in motor balance, any knowledge of the functioning of the system of organs and the possibility of identifying any active factors are used in testing. The risk factors for motor balance deficits could originate internally (the body) or from external surroundings. Internal factors include obstructions to the function of the cardiovascular, neuromuscular and perceptive system, the use of orthopedic aids, psychological experiences and cognitive functions.

Many studies (8-11) have investigated the effects of various forms of exercise on changes in the function of various systems of organs since they influence the development and maintenance of postural stability either during quiet standing or during motion. Various combinations of several exercises, all used for varying purposes, were usually used as experimental factors. The results of this kind of research usually corroborated the assumptions that the exercises that were used could develop and maintain the abilities of an athlete at a higher level than that of a non-athlete. During the course of this research we used dance structures as the factor affecting changes in balance, as these structures demand, among other things, both static and dynamic balance. The aim of this study was to determine the effects of Greek folk dances on postural stability in middle aged women. We hypothesize that this kind of study would give us an answer to whether organized Greek folk dance exercise can cause changes in the ability of women to sustain static and dynamic balance.

\section{MATERIALS AND METHODS}

\section{Participants}

Sixty-three women from Athens (the municipality of Patrisia), aged from 47 to 53, participated in this study. All participants were randomly divided into the experimental group - 33 participants $($ mean $\pm \mathrm{SD}$; body height $=160.13 \pm 12.07 \mathrm{~cm}$, body mass $=63.81$ $\pm 10.56 \mathrm{~kg}$ ), and the control group -30 participants (mean $\pm \mathrm{SD}$; body height $=160.63 \pm 6.22 \mathrm{~cm}$, body mass $=64.79 \pm 8.19 \mathrm{~kg}$ ). All subjects in the experimental group actively participated in the experimental exercise programme consisting of Greek folk dances, and the subjects in the control group neither exercised in a systematic manner nor danced during the course of the experiment. All participants included in this study continued with their habitual lifestyle in addition to the training programme for the experimental group or no exercise for the control group. No attempt was made to control the subjects in their occasional individual exercise or dance sessions.

All participants met the basic requirement for participating in the experiment - they were all healthy. Special measures were taken to exclude any participants with arthritic foot disorders from the study. All participants gave their consent for the testing or inclusion in the study, and the participants in the experimental group agreed to practice folk dancing three times a week for the duration of the experiment. The study was approved by the Ethics Committee of the Faculty of Sport and Physical Education, University of Niš according to the Helsinki Declaration. Participants were fully informed and were aware that they could withdraw from the study at any time.

\section{Procedures}

Basic anthropometric parameters (stature and body mass) were registered in the study protocol. Each subject performed a standardized 15 minute warm-up consisting of general movements and dynamic and static stretching. After the general warm-up, subjects performed assessments of static and dynamic balance randomly and the order in which the subjects performed the assessments were recorded to ensure the same order would be replicated for the final testing. The final testing was performed two days after the training session to avoid fatigue having an undue influence on participants performances. Participants underwent a series of physical test assessments in an indoor stadium. Before each testing the subjects performed a standard 15 minute warm-up. During the test air temperature ranged from $22^{\circ} \mathrm{C}$ to $25^{\circ} \mathrm{C}$. It began at 10 a.m. and finished by 1 p.m. Subjects were instructed not to be involved in strenuous exercise for at least 48 hours before the balance testing session and to consume their normal pre-training diet before the testing session.

The following tests were used to evaluate the motor balance of participants:

- to evaluate posture stability: the double-leg stance along the length of a balance beam (eyes open) (2LOBB), the doubleleg stance along the width of a balance beam (eyes open) (2WOBB), the single-leg stance (eyes open) (FLAM), and the double-leg stance on one's toes (eyes closed) (2TOE);

- to evaluate dynamic balance: the Functional Reach Test for balance (FRT) and the Star Excursion Balance Test (SEBT).

The double-leg stance along the length of a balance beam. A balance beam is a board $2 \mathrm{~cm}$ wide, $4 \mathrm{~cm}$ high and $60 \mathrm{~cm}$ long, which is fastened to a thicker board with dimensions of $60 \times 30 \mathrm{~cm}$. Leaning onto the shoulders of the investigator or someone else, the participants were asked to stand barefoot along the length of the balance beam, in a tandem stance with one foot behind the other. Once they assumed the balanced stand, they placed both hands on their hips, in an eyes-open position. The participants were asked to sustain the balance stance for as long as possible. The test was repeated three times. Trials were considered over if the participants fell of the beam or lifted their hands off their hips. The performances were measured in tenths of a second, starting when the subject assumed the balance stand until the balance was disrupted (12). The trial was repeated three times and the average was calculated.

The double-leg stance along the width of a balance beam. Leaning onto the shoulders of the investigator or someone else, the participants were asked to stand barefoot in a double-leg stance along the width of the balance beam, with their eyes open, leaning onto the front part of both feet (12). Once they assumed the balanced stand, they placed both hands on their hips. The participants were asked to sustain the stance position for as long as possible. The test was repeated three times. Trials were considered over if the participants fell of the beam or lifted their hands off their hips. The performances were measured in tenths of a second, starting when the subject took the balance stand until the balance was disrupted. The trial was repeated three times and the average was calculated.

The single-leg stance (Flamingo). The participants were asked to stand barefoot along the whole length of one foot in a single-leg stance, with their eyes opened. They were asked to place their other foot next to the knee of their stance limb. Their hands were 
fixed on their thighs. The participants were asked to sustain the stance position for as long as possible. Trials were considered over if the participants separated their foot from their knee or moved their hands off their thighs. The performances were measured in tenths of a second, starting when the subject took the balance stand until the balance was disrupted (12).

The double-leg stance on one's toes. The participants were asked to assume a double-leg stance leaning on the front part of both feet, with their eyes closed (12). After assuming the balanced stand they placed their hands on their hips. The participants were asked to sustain the stance position for as long as possible. Trials were considered over if the participants placed their entire foot on the floor or moved their hands off their thighs. The performances were measured in tenths of a second, starting when the subject took the balance stand until the balance was disrupted. The trial was repeated three times and the average was calculated.

The Functional Reach Test for balance. The test was constructed by Duncan et al. (5) to measure balance, stability and balancing during a functional task. Previous studies have shown this test to have high reliability and validitiy (13). A stick was placed on the wall for measuring a length parallel to the floor, which we fixed at specific height, and drew a line on the floor at a 90 degrees angle. Each participant was asked to stand sideways towards the wall at a distance of $30.5 \mathrm{~cm}$ behind the line drawn on the floor, with their feet at shoulder width and arms at their sides. The participants were then instructed to reach their dominant hand out toward the wall. Clenching their hands into a fist, the participants then moved their arms by about 90 degrees. The participants were then asked to reach with the top of their metacarpal bone as far forward along the measuring line as possible without moving their body forwards or backwards. The measured distance was taken as the initial measurement. The participants were then asked to try to reach forward along the measuring line without moving their feet. This was taken as the final measurement. We allowed any reach strategy which did not require moving the feet. The trial was repeated three times. The difference between the initial and final value made up the reach result or the dynamic balance. Results were noted in centimetres $(\mathrm{cm})$.

Star Excursion Balance Test. Using a tape, a grid was constructed on the floor with eight lines extending at 45 degrees increments from the centre of the grid (14). The lines of the grid were enclosed by a square which one side measured $182.9 \mathrm{~cm}$ in length. Eight lines were positioned in relation to the direction of their reach and were named: anterior (A), anteromedial (AM), lateral (L), posterolateral (L), posterior (P), posteromedial (PM), medial $(\mathrm{M})$, and anteromedial (AM). The investigator gave a verbal and visual demonstration, after which each subject was allowed a practice trial in each of the directions. The participants were asked to perform the test first with their right leg (their left leg was their stance limb) and then with their left leg (their right leg was their stance limb), both times barefoot. When their stance limb was their left leg, the participants were asked to reach the leg to the endpoints as near as possible, moving clockwise from one line to the other. When their stance limb was their right leg, the participants were asked to reach the endpoints with their left leg, moving counter-clockwise.

We asked the participants, while maintaining a single-leg stance, to reach the endpoint of each line with the tips of their toes as near as possible, trying not to disrupt the stability and neuromuscular control of the stance limb. The participants then returned their leg to the centre of the grid. Reaching for the endpoint was repeated for each eight lines, first with one leg, then with the other. The trials were repeated if the participants touched any point on the line other than the endpoint, if they moved the foot of their stance limb or lifted themselves onto their toes, if balance was lost at any point during the trial or if the final position was not maintained for one full second. During the trial, the participants were free to move their arms, and they could bend the knee of their stance limb if necessary. In addition, they were accordingly allowed to move their body.

There was a 15 minute break between two trials. The reaches from the centre of the grid were recorded three times in each direction. We calculated the average of three reaches for each direction in centimeters, resulting in eight parameters for the left leg and eight for the right, a total of 16 parameters for both legs. All 16 parameters were taken into consideration (Figure 1).

While standing on her left leg, the subject reached for the endpoints on the grid with her right leg (the tips of her foot) in the following order: anterior (RA), anterolateral (RAL), lateral (RL), posterolateral (RPL), posterior (RP), posteromedial (RPM), medial (RM), and anteromedial (RAM). While standing on her right leg, the subject reached for the endpoints of the grid with her left leg (the tips of her foot) in the following order: anterior (LA), anterolateral (LAL), lateral (LL), posterolateral (LPL),
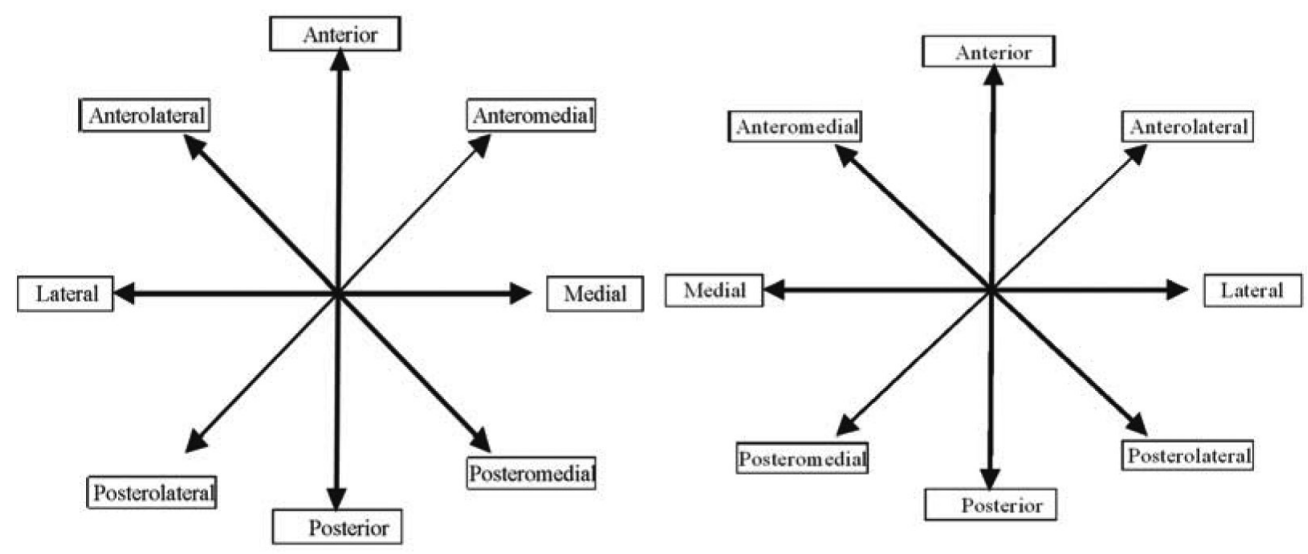

Fig. 1. Star Excursion Balance Test parameters. 
Table 1. Experimental dance exercise programme

\begin{tabular}{|c|c|c|}
\hline & $\begin{array}{l}\text { Goal: dance teaching classes } \\
\text { Week 1-3 }\end{array}$ & $\begin{array}{l}\text { Goal: dance training classes } \\
\text { Week 4-12 }\end{array}$ \\
\hline \multicolumn{3}{|l|}{ Warm-up } \\
\hline Intensity & $50-60 \%$ HRmax & $50-60 \%$ HRmax \\
\hline Duration & $15 \min$ & $10 \mathrm{~min}$ \\
\hline Exercises description & jogging, stretching and calisthenics exercises & jogging, stretching and calisthenics exercises \\
\hline \multicolumn{3}{|l|}{ Main part } \\
\hline Intensity & $60-75 \%$ HRmax & $70-85 \%$ HRmax \\
\hline Duration & $35 \mathrm{~min}$ & $2 \times 20$ min; 5 min rest \\
\hline Exercises description & learning the dance & dance training \\
\hline \multicolumn{3}{|l|}{ Cool down } \\
\hline Intensity & $50-60 \%$ HRmax & $50-60 \%$ HRmax \\
\hline Duration & $10 \mathrm{~min}$ & $10 \mathrm{~min}$ \\
\hline Exercises description & relaxation activities and leg stretching exercises & relaxation activities and leg stretching exercises \\
\hline
\end{tabular}

Table 2. Differences between static and dynamic balance between experimental and control group

\begin{tabular}{|c|c|c|c|c|}
\hline & \multicolumn{2}{|c|}{ Experimental group $(n=33)$} & \multicolumn{2}{|c|}{ Control group $(n=30)$} \\
\hline & $\begin{array}{c}\text { Initial } \\
(\text { Mean } \pm S D)\end{array}$ & $\begin{array}{c}\text { Final } \\
(\text { Mean } \pm S D)\end{array}$ & $\begin{array}{c}\text { Initial } \\
\text { (Mean } \pm \text { SD) }\end{array}$ & $\begin{array}{c}\text { Final } \\
(\text { Mean } \pm S D)\end{array}$ \\
\hline 2LOBB (sec) & $64.47 \pm 28.57$ & $75.44 \pm 31.64$ & $55.15 \pm 28.77$ & $53.99 \pm 28.64$ * \\
\hline 2WOBB (sec) & $51.03 \pm 28.68$ & $75.13 \pm 22.22$ & $43.85 \pm 29.06$ & $42.07 \pm 27.56$ * \\
\hline FLAM (sec) & $1143.95 \pm 480.08$ & $1242.46 \pm 493.47$ & $1136.75 \pm 444.45$ & $1137.20 \pm 431.72$ \\
\hline 2TOE (sec) & $53.43 \pm 23.05$ & $77.81 \pm 16.17^{*}$ & $50.64 \pm 29.74$ & $49.92 \pm 25.78^{*}$ \\
\hline FRT (cm) & $43.01 \pm 11.88$ & $61.38 \pm 14.53^{*}$ & $44.21 \pm 6.71$ & $44.16 \pm 6.74$ * \\
\hline \multicolumn{5}{|c|}{ Star Excursion Balance Test (cm) } \\
\hline Anterior & $107.92 \pm 17.98$ & $113.47 \pm 14.89$ & $105.49 \pm 18.96$ & $104.71 \pm 18.91$ \\
\hline Anterolateral & $116.91 \pm 14.85$ & $123.46 \pm 10.11$ * & $113.16 \pm 17.59$ & $111.44 \pm 17.44$ * \\
\hline Lateral & $124.31 \pm 17.41$ & $127.99 \pm 15.24$ & $120.65 \pm 18.87$ & $122.65 \pm 23.64$ \\
\hline Posterolateral & $126.73 \pm 19.84$ & $131.19 \pm 17.06$ * & $121.49 \pm 22.07$ & $120.44 \pm 21.81$ \\
\hline Posterior & $125.07 \pm 25.06$ & $132.30 \pm 20.58$ & $120.64 \pm 27.87$ & $114.28 \pm 25.96$ \\
\hline Posteromedial & $139.15 \pm 169.22$ & $111.73 \pm 20.60$ * & $102.07 \pm 27.22$ & $99.63 \pm 29.44$ \\
\hline Medial & $77.81 \pm 16.60$ & $78.21 \pm 16.37$ & $66.67 \pm 17.04$ & $64.31 \pm 19.79$ * \\
\hline Anteromedial & $43.45 \pm 17.50$ & $51.10 \pm 13.75$ & $37.33 \pm 13.05$ & $41.52 \pm 19.10$ * \\
\hline Anterior & $110.23 \pm 21.16$ & $111.96 \pm 21.52$ & $109.55 \pm 19.22$ & $109.24 \pm 19.05$ \\
\hline Anterolateral & $117.95 \pm 13.89$ & $120.38 \pm 13.13$ & $114.38 \pm 14.06$ & $113.69 \pm 14.18$ \\
\hline Lateral & $125.59 \pm 16.01$ & $128.82 \pm 15.25$ & $123.03 \pm 16.95$ & $122.36 \pm 17.12$ \\
\hline Posterolateral & $127.28 \pm 17.28$ & $131.45 \pm 19.92$ & $123.68 \pm 19.34$ & $123.31 \pm 19.07$ \\
\hline Posterior & $127.00 \pm 17.48$ & $129.06 \pm 16.98$ & $118.13 \pm 20.84$ & $115.10 \pm 21.87$ * \\
\hline Posteromedial & $107.77 \pm 14.07$ & $109.35 \pm 14.69$ & $101.84 \pm 22.43$ & $98.44 \pm 24.10$ \\
\hline Medial & $73.36 \pm 17.34$ & $77.33 \pm 15.55$ & $66.32 \pm 17.07$ & $61.97 \pm 20.11$ * \\
\hline Anteromedial & $47.77 \pm 17.97$ & $56.50 \pm 20.47$ & $40.69 \pm 15.57$ & $40.29 \pm 15.69$ * \\
\hline
\end{tabular}

${ }^{*}$ Significant difference $(p<0.05)$ between initial and final testing; 2LOBB - double-leg stance along the length of a balance beam (eyes open), 2WOBB - double-leg stance along the width of a balance beam (eyes open), FLAM - single-leg stance (eyes open), 2TOE - double-leg stance on one's toes (eyes closed), FRT - Functional Reach Test for balance

Table 3. Multivariate variance analysis of motorical balance between experimental and control group on initial measurement

\begin{tabular}{|c|c|c|}
\hline Wilks' lambda & $\mathbf{F}(26,39)$ & $\mathbf{p}$ \\
\hline 0.65 & 0.78 & 0.74 \\
\hline
\end{tabular}

Table 4. Multivariate variance analysis of motorical balance between experimental and control group on final measurement

\begin{tabular}{|c|c|c|}
\hline Wilks' lambda & $\mathrm{F}(26,35)$ & $\mathrm{p}$ \\
\hline 0.32 & 2.83 & 0.002 \\
\hline
\end{tabular}


Table 5. Multivariate covariance analysis of motorical balance between experimental and control group on final measurement

\begin{tabular}{|c|c|c|c|c|}
\hline Wilks' lambda & Rao's R & Df1 & Df2 & p \\
\hline 0.45 & 2.87 & 13 & 33 & $<0.001$ \\
\hline
\end{tabular}

posterior (LP), posteromedial (LPM), medial (LM), and anteromedial (LAM).

All tests used in this study were reliable and valid to assess static and dynamic balance $(5,12-14)$.

\section{Training Programme}

The programme consisted of a total of 34 hours of recreational exercise - Greek folk dancing (Table 1). The participants exercised for three hours each week. All participants were tested prior to the start of the experimental programme. Out of the 34hour experimental programme, 10 hours were spent teaching the participants the various folk dance structures, while the remaining 24 were used for practice and training.

During these classes, we used the folk dance music that was going to be used in the experimental programme. The programme consisted of the following folk dances: Sirtos Makedonias, Tsamikos, Fisuni, Hasapiko, Kalamatiano, Balos, Koftos, Bajduska, and Sirto sta tria. The participants were asked to perform the basic dance steps as well as numerous variations of these steps. Our choice of dances was based on the dance technique involved and the rhythm of steps. We took care to not repeat the same techniques and rhythms in different dances. The dance technique consisted of steps, jumps and turns as well as the combinations of these elements performed to the rhythm and dance tempo of individual dances. Every lesson had a similar tempo ranging from slow ( 72 beats per minute) to moderate (114 beats per minute) or fast 184 (beats per minute). The slow tempo was used for the initial phase of the lesson whilst the moderate and fast tempos were constantly switched between to avoid constant high-intensity activites and accumulation of fatigue, during the main phase.

\section{Statistical Analysis}

The Statistical Package for Social Sciences SPSS (v18.0, SPSS Inc., Chicago, IL) was used for the statistical analysis. Descriptive statistics were calculated for all experimental data. To determine whether statistically significant differences existed between the means of the experimental and control groups initial and final measurement, we used a multivariate and univariate analyses of variance (MANOVA/ANOVA). The differences between the initial and final measurements of the experimental and control groups were determined using the t-test. For the purpose of determining the effects of exercise following the completion of the exercise programme, a multivariate analysis of covariance (MANCOVA) and univariate analysis of covariance (ANCOVA) were used. Statistical significance was accepted for values of $\mathrm{p}<0.05$.

\section{RESULTS}

The means and standard deviations for the measures of static and dynamic balance parameters of the participants in the control and experimental group at the initial and final measuring are shown in Table 2. By determining the differences in motor balance between the experimental and control group at the initial measuring (Wilks' lambda=0.65), we have concluded that no significant intergroup differences exist in relation to static and dynamic balance $(\mathrm{p}=0.74)$ (Table 3$)$. We found similar levels of static and dynamic balance for the experimental and control group at the first measuring.

By determining the differences in static and dynamic balance between the control and experimental group at the final measuring (Wilks' lambda $=0.32$ ), we have concluded that there are significant intergroup difference $(p=0.002)$ (Table 4). The intergroup difference at the final measuring was found to be statistically significant $(\mathrm{p}<0.05)$ for the following variables: the double-leg stance on one's toes (2TOE), the Functional Reach Test (FRT), balance of the right anterolateral (RAL), balance of the right posterolateral (RPL), and balance of the left posteromedial (LPM).

The multivariate analysis of covariance of static and dynamic balance between participants of the experimental and control group at the final measuring, with neutralized differences at the initial measuring (Wilks' lambda $=0.45$ ), revealed a significant difference $(\mathrm{p}<0.001)$ (Table 5).

The ANCOVA revealed significant differences for the following variables: the double-leg stance along the length of a balance beam $(2 \mathrm{LOBB} ; \mathrm{p}=0.02)$, the double-leg stance on one's toes $(2 \mathrm{TOE} ; \mathrm{p}<0.001)$, the Functional Reach Test for balance (FRT; $p<0.001$ ), balance of the anterolateral (RAL; $p=0.01$ ), balance of the right medial (RM; $p=0.01$ ), balance of the anteromedial (RAM; $p<0.001$ ), balance of the left posterior (LP; $p<0.05$ ), balance of the left medial (LM; $<<0.05)$, and balance of the left anteromedial (LAM; $\mathrm{p}<0.001)$.

\section{DISCUSSION}

The experimental programme we used in this study consisted of Greek folk dances, which participants of the experimental group practiced in a systematic and regular manner during the course of experimental treatment. There is extensive research on what activities involving movement were used to determine any possible effect on the improvement on static and dynamic balance.

At the initial measuring, there were no significant differences in motor balance between the experimental and control groups consisting of women living in Athens at the multivariate level. Our results were expected, considering the fact that neither group of participants had exercised in a systematic or organized manner prior to this measuring, and had only occasionally trained in a gym, and for the most part, the majority had walked and performed motor activities as part of their everyday routines in their homes and in society. After the partialization of results at the final measuring, our results showed a statistically significant difference between the groups. They revealed that the experimental programme consisting of Greek folk dances probably led to an improvement in the static and dynamic balance of women. Other studies (15-18) also found positive results in postural control after physical intervention targeting the elderly. After 10 weeks of exercise, Carter et al. (15) demonstrated that the experimental group achieved better results for static and dynamic balance, but that these results were not statistically significant. Practicing Tai 
Chi led to a significant improvement in dynamic balance measured with help of the Functional Arm Reach Test after 12 weeks of exercise, as demonstrated by Thornton et al. (17). Li et al. (16) also demonstrated the effects of Tai Chi exercises on functional balance on the basis of a six-month exercise programme. This kind of exercise has proven to be a good means of preventing falls among elderly women. The results of research carried out by Karinkanta et al. (18) have demonstrated that well-developed lower extremity musculature and dynamic balance are independent factors important for good quality of life among elderly women. Three different exercise programmes ("ballates", step-aerobics and walking) used in the research carried out by Clary et al. (19) have demonstrated a positive effect on the level of dynamic balance, which showed signs of statistically significant improvement among women aged from 50-75. Holviala et al. (20) studied the effects of 21 weeks of progressive strength training on the dynamic balance of elderly men and women, and concluded that this kind of dynamic strength training can be used as rehabilitation or prevention exercise for elderly women, with the aim to achieve better dynamic balance. Burke et al. (21) assessed the efficacy of 8 weeks exercise programme aiming to improve balance and muscular strength of lower limbs, for postural control of 33 women with osteoporosis. Results showed postural control improvement in the intervention group. Postural control of 50 women aged 65 years or older with osteoporosis was assessed and the results of 8 week intervention programme (balance training with muscle strengthening and with stretching) suggested that both interventions are effective in improving postural control (21).

This study was carried out to demonstrate the effects of the above described intervention programme on the motor functions of women living in Athens, and the results revealed a positive effect of an organized, planned and systematic Greek folk dance programme. Our results showed statistically significant differences in motor balance between the initial and final measuring of the experimental group and the initial and final measuring of the control group. In case of the experimental group, the quantitative parameter of significance was better compared to the control group.

Considering the fact that we obtained a statistically significant difference in postural stability between the initial and final measuring of the control group, we assume that this difference can be explained by taking various aspects into consideration. Primarily, our subsamples did not share the same motivation. The participants of the control group were not controlled and were free to participate in various forms of exercise, while the participants in the experimental group only danced. In addition, there is the possibility that good and bad results can be obtained with more rational body and arm movements and the corresponding knee bends that are part of the execution of certain tasks in the balance tests. We cannot forget the importance of focused attention, not to mention some other factors related to the strength or mobility of the joint-muscular system, primarily of the legs. We did not take into consideration the strength and range of motion of the leg muscles and joints as well as foot type, nonetheless, we assume that they play a special part in maintaining balance (especially the dynamic kind).

When Cote et al. considered foot type (pronated, supinated, and neutral) in their study (14), they concluded that foot type was not directly linked to balance. Ringsberg et al. (22) believe that leg muscle strength is not necessarily connected to balance.
Studies dealing with the relations between stable and unstable joints and static and dynamic balance of the body have revealed that participants with functionally unstable joints need more time to stabilize after landing following a jump on one leg than the participants with stable joints (23).

Nevertheless, our results are quite logical if we take into consideration the experimental programme as well as the structure of the folk dances which the participants danced. The dances consisted of various steps, various hops and various steps and turns, which could be combined in various ways. The participants performed most of the elements by placing their feet in different positions and by differently distributing their weight on their feet, so we can assume that these combined factors had an effect on our results.

The presented dance techniques improve neuromuscular coordination, joint strength and joint range of motion, and those mechanisms led to improved balance $(24,25)$. Balance training through dancing reduces the risk of some musculoskeletal injuries, such as ankle sprains, especially if one or more balance components are not optimal at the start (26).

Due to the positive changes in motor balance, we can recommend exercise based on folk dances as an activity which is suitable for static and dynamic balance improvement. Considering the importance of balance and postural stability for women around the age of 50, we have concluded that the results are significant from the aspect of programme verification, primarily recreational programmes based on Greek folk dances. This study stuggests that an organized dance activity programme does lead to the improvement of static and dynamic balance.

\section{REFERENCES}

1. Hatzitaki V, Zlsi V, Kollias I, Kioumourtzoglou E. Perceptual-motor contributions to static and dynamic balance control in children. J Mot Behav. 2002 Jun;34(2):161-70.

2. Venetsanou F, Kambas A. The effects of age and gender on balance skills in preschool children. Facta Univ Ser Phys Educ Sports. 2011;9(1):81-90.

3. Büla CJ, Monod S, Hoskovec C, Rochat S. Interventions aiming at balance confidence improvement in older adults: an updated review. Gerontology. 2011;57(3):276-86.

4. Mohapatra S. Role of altered vision and proprioception in control of posture [dissertation]. Chicago: University of Illinois at Chicago; 2012.

5. Duncan PW, Weiner DK, Chandler J, Studenski S. Functional reach: a new clinical measure of balance. J Gerontol. 1990 Nov;45(6):M192-7.

6. Sheets-Johnstone M. The primacy of movement. Amstedam: John Benjamins Publishing Company; 2011.

7. Gribble PA, Tucker WS, White PA. Time-of-day influences on static and dynamic postural control. J Athl Train. 2007 Jan-Mar;42(1):35-41.

8. Bellew JW, Yates JW, Gater DR. The initial effects of low-volume strength training on balance in untrained older men and women. J Strength Cond Res. 2003 Feb;17(1):121-8.

9. Hinman MR. Comparison of two short-term balance training programs for community-dwelling older adults. J Geriatr Phys Ther. 2002;25(3):10$5 ; 20$.

10. Judge JO, Lindsey C, Underwood M, Winsemius D. Balance improvements in older women: effects of exercise training. Phys Ther. 1993 Apr;73(4):254-62.

11. Komagata S, Newton R. The effectiveness of Tai Chi on improving balance in older adults: an evidence-based review. J Geriatr Phys Ther. 2003;26(2):9-16.

12. Tkalčić S, Hošek A, Šadura T, Dujmović P. Metric characteristics of instruments for balance measurement. Kineziologija. 1974;4(2):53-65. (In Croatian.)

13. Light KE, Rose DK, Purser JL. The Functional Reach Test for balance: strategies of elderly subjects with and without disequilibrium. Phys Occup Ther Geriatr. 1996;14(1):39-52. 
14. Cote KP, Brunet ME, Gansneder BM, Shultz SJ. Effects of pronated and supinated foot postures on static and dynamic postural stability. J Athl Train. 2005 Mar;40(1):41-6.

15. Carter ND, Khan KM, Petit MA, Heinonen A, Waterman C, Donaldson MG, et al. Results of a 10 week community based strength and balance training programme to reduce fall risk factors: a randomised controlled trial in 65-75 year old women with osteoporosis. Br J Sports Med. 2001 Oct;35(5):348-51.

16. Li F, Harmer P, Fisher KJ, McAuley E. Tai Chi: improving functional balance and predicting subsequent falls in older persons. Med Sci Sports Exerc. 2004 Dec;36(12):2046-52.

17. Thornton EW, Sykes KS, Tang WK. Health benefits of Tai Chi exercise: improved balance and blood pressure in middle-aged women. Health Promot Int. 2004 Mar;19(1):33-8.

18. Karinkanta S, Heinonen A, Sievanen H, Uusi-Rasi K, Kannus P. Factors predicting dynamic balance and quality of life in home-dwelling elderly women. Gerontology. 2005 Mar-Apr;51(2):116-21.

19. Clary S, Barnes C, Bemben D, Knehans A, Bemben M. Effects of ballates, step aerobics, and walking on balance in women aged 50-75 years J Sports Sci Med. 2006 Sep 1;5(3):390-9.

20. Holviala JH, Sallinen JM, Kraemer WJ, Alen MJ, Häkkinen KK. Effects of strength training on muscle strength characteristics, functional capabilities, and balance in middle-aged and older women. J Strength Cond Res. 2006 May;20(2):336-44.
21. Burke TN, França FJ, Meneses SR, Pereira RM, Marques AP. Postura control in elderly women with osteoporosis: comparison of balance, strengthening and stretching exercises. A randomized controlled trial. Clin Rehabil. 2012 Nov;26(11):1021-31.

22. Ringsberg K, Gerdhem P, Johansson J, Obrant KJ. Is there a relationship between balance, gait performance and muscular strength in 75-year-old women? Age Ageing. 1999 May;28(3):289-93.

23. Ross SE, Guskiewicz KM. Examination of static and dynamic postura stability in individuals with functionally stable and unstable ankles. Clin J Sport Med. 2004 Nov;14(6):332-8.

24. Ashton-Miller JA, Wojtys EM, Huston LJ, Fry-Welch D. Can proprioception really be improved by exercises? Knee Surg Sports Traumatol Arthrosc. 2001 May;9(3):128-36.

25. Balter SG, Stokroos RJ, Akkermans E, Kingma H. Habituation to galvanic vestibular stimulation for analysis of postural control abilities in gymnasts. Neurosci Lett. 2004 Aug 5;366(1):71-5.

26. Bressel E, Yonker JC, Kras J, Heath EM. Comparison of static and dynamic balance in female collegiate soccer, basketball, and gymnastics athletes. J Athl Train. 2007 Jan-Mar;42(1):42-6.

Received November 24, 2014 Accepted in revised form May 29, 2015 